\title{
Nutritional and sensory properties of co-fermented maize, millet and sorghum/soybean pap-(ogi)
}

\begin{abstract}
Traditional complementary foods based on cereals alone lack adequate nutrients required by the infants and the deficiencies of essential nutrients in diets of infants can cause poor growth, development and diseases. Co-fermentation of cereals/ soybean ogi is a cheap household processing method that enhances food quality and nutrition security. This study investigated the nutritional and sensory properties of cereals/soybean pap (ogi). Grains of cereals and soybean were weighed and mixed in the ratio $1: 2 \mathrm{w} / \mathrm{w}$ (for soybean: cereals).The mixture was fermented for three days, washed, wet milled and sieved, while the same quantity of each unfermented cereal/ soybean mixtures were used as controls. Proximate and nutrient compositions as well as anti-nutrient content of the gruel mixtures were determined using official standard method. Sensory properties were determined using 9-point Hedonic scale ranging from like extremely to dislike extremely. The results showed that all the fermented cereals/soybean ogi contained significantly higher crude protein, fat, ash and moisture than its unfermented counterparts. On the other hand, fermentation had a decreasing effect on the crude fibre content of cereals/soybean ogi. All unfermented ogi recorded higher calcium content than its fermented analogues except for FSGSB. Similarly, unfermented cereal/soybean ogi recorded higher amount of potassium and magnesium when compared with its co-fermented analogues. Unfermented sorghum/soybean ogi (USGSB) was top-ranked with the highest value of $512.13 \mathrm{mg} / \mathrm{kg} \mathrm{K}$ and $345.59 \mathrm{mg} / \mathrm{kg}$ $\mathrm{Mg}$. Conversely, FMLSB and FSGSB were the only samples with higher iron and zinc content respectively than its unfermented counterpart. Other micro elements followed the same trend, in which the unfermented samples had higher amount of $\mathrm{Cu}$ and $\mathrm{Zn}$ than its counterparts. All co-fermented cereals/soybean ogi contained significantly lower phytate and tannin level than their respective counterparts. Sensorially, FMZSB was the most preferred sample while USGSB pap and its fermented counterpart were relatively higher in mineral elements. Right choice of the cereals/soybean combination will be the best complementary food for infants.
\end{abstract}

Keywords: fermentation, ogi, maize, millet, sorghum, soybean, nutrient elements
Research Article

Volume 6 Issue I - 2018

\author{
Emmanuel C Omenna, I Oyeyoyin T \\ Olanipekun, I Funmilayo J Ogunwale2 \\ IInstitute of Agricultural Research and Training, Obafemi Awolowo \\ University, Nigeria \\ 2Federal College of Agricultural, Nigeria
}

Correspondence: Emmanuel C Omenna, Institute of Agricultural Research and Training, Obafemi Awolowo University, P.M.B.5029. Moor Plantation, Ibadan, Nigeria, Tel +2348039334092, Email emmanuelomenna@gmail.com

Received: October 26, 2017| Published: February 28, 2018
Abbreviations: FMZSB, fermented maize/soybean; UMZSB, unfermented maize/soybean; FMLSB, fermented millet/soybean; UMLSB, unfermented millet/soybean; FSGSB, fermented sorghum/ soybean USGSB, unfermented sorghum/soybean; HND, higher national diploma; IAR\&T, institute of agricultural research and training; LSD, least significant difference; HDL, high-density lipoprotein

\section{Introduction}

The cost of baby formula is currently high beyond the reach of low or average income household mothers and the traditional complementary foods based on cereals alone usually have inadequate nutrients required by the infants. Ogi is a popular weaning food and also a breakfast meal in Nigeria especially in the south-western part of Nigeria. Ogi is a locally made smooth creamy, free-flowing thin porridge of fermented cereals like maize, sorghum and millet. Complementary foods are used to meet the infant nutritional requirement, when mother's milk is no longer adequate to meet its nutritional requirement after the exclusive period of breastfeeding. However, the purpose and types of processing used in preparing complementary foods for infants should be for separation and purification of the edible parts of raw material and most importantly, it should also improve the nutritional qualities and reduce the anti- nutrient factors. ${ }^{1}$ The low socio-economic status mothers are not well informed about the unfolding nutritional benefits of co-fermented cereal /soybean-ogi. It is therefore desirable to formulate a processing method in which cereals and soybean can be jointly processed to reduce labour, cost, energy and loss of nutrients that could arise from the separate processing of cereals and soybean.

Many efforts have been made to improve the nutritive value of cereals by supplementation with legumes. ${ }^{1}$ Reported that cereals/ cowpea mixture provided the highest quality of protein at ratio $3: 1$. Similarly, ${ }^{2}$ reported that supplementation before fermentation (cofermentation) had improved protein, fat ash and crude fibre contents of the gruel. Many publications showed that the most acceptable products for infant complementary foods were those containing the dehulled legume and cereal in a ratio 70:30 and this had the best overall organoleptic acceptability. ${ }^{3}$ Similarly, ${ }^{1}$ reported that co-fermentation had significantly increased mineral contents and organoleptic properties of cereals/cowpea-ogi. Despite the unfolding benefits of co-fermentation, there is little or limited information particularly on the nutritional status and sensory properties of the traditionally cofermented cereals/soybean-ogi. Hence, this study tends to bridge the existing gap. The knowledge of this common household practice (cofermentation) will be useful in the fight against malnutrition, food and nutrition insecurity. 


\section{Materials and methods}

\section{source of material}

Maize (Zea mays), Sorghum (Sorghum vulgare), Millet (Pennisetum glaucum) and Soybean (Glycine max) were all purchased from a local market Omi-Adio in Ibadan, Oyo State. Nigeria.

\section{sample preparation}

The cereals (maize, millet \& sorghum) and soybean were mixed in the ratio $2: 1(\mathrm{w} / \mathrm{w})$. The mixture was soaked in tepid water for three days after which each mixture was wet milled, sieved and allowed to stand in steeping water for 24 hours. The supernatant was decanted leaving slurry. The slurry of each mixture was dewatered. A ratio of about 1:4 (slurry: water) was mixed and boiled for about 15 minutes. The sample mixtures were tagged as follows:

1. Fermented maize/soybean $=$ FMZSB; unfermented maize/ soybean $=\mathrm{UMZSB}$

2. Fermented millet/soybean $=$ FMLSB; unfermented millet/ soybean=UMLSB

3. Fermented sorghum/soybean=FSGSB; unfermented sorghum/soybean=USGSB

\section{sensory evaluation}

The boiled gruel was allowed to cool to about $45^{\circ} \mathrm{C}$. Gruel from all ogi samples were evaluated for organoleptic characteristics and overall acceptability by thirty (30) panelists that comprised of randomly selected Higher National Diploma(HND) students, teaching and non-teaching staff members of Federal College of Agriculture and the Institute of Agricultural Research and Training (IAR\&T), Moor Plantation, Oyo State, Nigeria; using nine point Hedonic Scale. Prior to each assessment, the participants were informed about the task of the test. In addition to the information, a detailed set of written instruction on testing method was available in each table. Ten grams $(10 \mathrm{~g})$ of cereals/soybean ogi were served to each participant coded in a plate. Panelists/participants were instructed to resin their mouths before tasting the next sample. Water and crisp beans cake (popularly called akara) were available as neutralizers. The same participants were used in all the steps of the sensory evaluation, so that accurate data collection could be obtained. Each panellist/participant was given a questionnaire bearing the sample code to complete after tasting the cereal/soybean-ogi samples. They were not told what each sample represented. The attributes tested were: *appearance-colour. *texturesmoothness. *Softness-soft. *taste-sweetness-sour, bitter. *mouth feel *aroma. *general acceptability.

\section{consumer acceptability survey}

Based on the outcome of the sensory evaluation, six different ogi mixtures were selected for the consumer preference test. Thirty consumers evaluated the cereals/soybean ogi for acceptability. Participants were consumers of cereal and legume foods. Six samples of ogi mixtures were presented to panelist on a white plastic plate with a unique 5-digit code. Salted fried bean cake (akara) and sachet of pure water were provided to clean and refresh the palate before evaluating different samples. Each panelist was made to assess each product based on the 9-point Hedonic scale (9=like very much, 1=dislike extremely) as check the rate product acceptability as described by Stone \& Sidel. ${ }^{4}$
Consumers were also given the option of writing their comments about the six products. Following the acceptability test, each consumer was also made to complete a questionnaire of closed ended questions. The questionnaire was used to collect information on consumer demography and product acceptability as shown in Table 1 .

Table I Demographic study profile

\begin{tabular}{llll}
\hline Variable & Frequency & Percentage (\%) & $\begin{array}{l}\text { Preferred } \\
\text { sample }\end{array}$ \\
\hline Gender & & & \\
Male & 16 & 53.33 & - \\
Female & 14 & 46.67 & \\
Age(n=30) & & & - \\
$<18$ & - & - & FMZSB \\
I8-25 & 20 & 66.67 & FMLSB \\
$26-33$ & 5 & 16.67 & FMZSB \\
$34-41$ & 1 & 3.33 & FMZSB \\
$42-49$ & 3 & 10 & FSGSB \\
50 above & I & 3.33 & - \\
Education level & - & - & - \\
Primary & - & 100 & - \\
Secondary & - & & \\
Tertiary & 30 & & \\
\hline
\end{tabular}

Abbreviations: FMZSB, fermented maize /soybean ogi; FMLSB, fermented millet/soybean ogi; FSGSB, fermented sorghum/soybean.

The hedonic 9-point scale is a useful tool to have for any examiner of food preference or overall liking of food. The scale is easy for the panelist to understand and use. The scale is self-explanatory with little instructions from the moderator of the test. ${ }^{5}$ Each panelist tastes a sample and decides whether or not they like it and then decides how much they like the sample. And subsequently, the panelist just picks the category/number that corresponds to their liking/disliking.

\section{nutrients analysis}

The metals were analyzed using Model 210 VGP of the Buck Scientific Atomic absorption Spectrophotometer (AAS) series with air-acetylene gas mixture as oxidant. Extracts from the above digestion were aspirated and the equipment calibrated for each element. The results were recorded as $\mathrm{mg} \mathrm{l}^{-1}$ of solution and were calculated to $\mathrm{mg}$ $\mathrm{kg}^{-1}$ of sample using the weight of sample taken as a denominator of the digest volume $(50 \mathrm{ml})$.

\section{Calculation}

$\mathrm{mg} \mathrm{kg}^{-1}$ sample $=$ digest conc. $\mathrm{x}$ DF, where digest conc. $=$ Analyte reading on AAS

$$
\mathrm{DF}=\frac{\text { Vol of digest } \times \text { aliquot }}{\text { Wt. of sample }}
$$

Where Vol. of digest $=$ Final volume of digested or extracted sample, Aliquot $=$ ratio of sample to distilled water (when diluted further), Weight of sample $=$ wt of sample taken for digestion or extract 


\section{proximate analysis}

According to $\mathrm{AOAC}^{6}$ each cereal/soybean sample was triplicated and analysed for proximate composition: dry matter, crude protein, crude fat, ash, crude fibre and mineral composition were determined. Carbohydrate was obtained by difference.

a. ash content: Five grams of cereal/soybean ogi samples were placed in a dry porcelain crucible, dried in a hot air oven for 16 $\mathrm{h}$. The dried sample was placed in a muffle furnace and ashed at temperature of around $525^{\circ} \mathrm{C}$ for $6 \mathrm{~h}$. The ash was then cooled in a desiccator and weighed. The weight was recorded as $\mathrm{g}$ per 100 $\mathrm{g}$ fresh weight. The determination was done in triplicate and the average value was recorded.

b. crude fat: The weighed dried ogi sample was put into a thimble and covered with fat free cotton. The thimble was then put into the soxhlet apparatus. The flask was filled with $150 \mathrm{~mL}$ petroleum ether and extraction was done for $16 \mathrm{~h}$. At the end the sample was dried at $100^{\circ} \mathrm{C}$ in an oven for $1 \mathrm{~h}$, then cooled to room temperature and re-weighed. The difference in the weights equals to the fatsoluble material present in the sample. Determinations were done in triplicate and the average value was recorded. ${ }^{7}$

c. crude fibres: Two grams of residue remaining from the crude fat determination was poured in a digestion flask followed by $200 \mathrm{~mL}$ of boiling $0.1275 \mathrm{M}$ sulphuric acid. The mixture in the flask was immediately connected to a condenser and the mixture heated for $30 \mathrm{~min}$. The material was then filtered and washed thoroughly with boiling distilled water until the washings were no longer acidic. A $0.313 \mathrm{M} \mathrm{NaOH}$ solution was boiled under reflux and the washed material added to it. The content in the flask were connected to the reflux condenser and boiled for $30 \mathrm{~min}$. The material was then filtered in a filtering cloth in a fluted funnel and washed thoroughly with distilled water followed by $15 \mathrm{~mL}$ of alcohol. The contents were finally dried at $110^{\circ} \mathrm{C}$ to a constant weight, cooled in a dessicator and weighed. The material was then ashed. The loss in weight represents the crude fibre amount of the fruit. The procedure of Ranganna ${ }^{7}$ was followed.

\section{determination of phytate in cereals/soybean pap}

Phytate was determined according to the method described by $\mathrm{Maga}^{8}$. Two grams of each sample was weighed into $250 \mathrm{ml}$ conical flask. $100 \mathrm{ml}$ of $2 \%$ hydrochloric acid was added to soak each sample in the conical flask for 3 hours. This was filter through double layers of hardened filter paper. $50 \mathrm{ml}$ of each filtrate was placed in $0.5 \mathrm{ml}$ conical and $107 \mathrm{ml}$ distilled water was added in each case. $10 \mathrm{ml}$ of $0.3 \%$ ammonium thiocyanate $\left(\mathrm{NH}_{4} \mathrm{SCN}\right)$ solution was added into each solution as indicated. This was titrated with standard iron (III) chloride solution which contained $0.00195 \mathrm{~g}$ Iron per $\mathrm{ml}$. The end point was slightly brownish-yellow which persist for 5 minutes. The percentage phytic acid was calculated using the formula:

$$
\% \text { Phytic acid }:=\frac{\text { Titre value } \times 0.00195 \times 1.19 \times 100 \times 3,55}{\text { üüü ample }}
$$

\section{determination of tannin content in cereals/cereal/ soybean pap}

About $0.2 \mathrm{~g}$ of each sample was measured into a $50 \mathrm{ml}$ beaker, $20 \mathrm{ml}$ of $50 \%$ methanol was added and covered with parafilm and placed in a water bath at $77-80^{\circ} \mathrm{C}$ for 1 hour. It was shaked thoroughly to ensure a uniform mixing. The extract was quantitatively filtered using a double layer Whatman No 41 filter paper into a $100 \mathrm{ml}$ volumetric flask, $20 \mathrm{ml}$ of distilled water was added, $2.5 \mathrm{ml}$ of Folin-Denis reagent and $10 \mathrm{ml}$ of $17 \% \mathrm{Na}_{2} \mathrm{CO}_{3}$ were added and mixed properly. The mixture was made up to mark with distilled water, mixed well and allowed to stand for 20minutes.The bluish-green colour was develop at the end of the range $0-10 \mathrm{ppm}$ where similar treatment was given as $1 \mathrm{ml}$ of the each sample. The absorbance of the tannin acid standard solutions as well as each sample was read after colour development on spectronic 21D spectrophotometer at a wavelength of $760 \mathrm{~nm}$.Percentage tannin was calculated using the formula

$\%$ Tannin : $=\frac{\text { Absorbance of sample } \times \text { Average gradient factors } \times \text { Dilution factor }}{\text { üüü } \quad \text { le üüü }}$

\section{statistical analysis}

Individual scores from panelists were averaged and the analysis of variance (ANOVA) was performed to determine significant differences between the means. The means were separated using the Fisher's Least Significant Difference (LSD) test and Duncan multiple range test at $P<0.05$.

\section{Results and discussion}

\section{demographic study of the questionnaire}

The Panelists who participated in the consumer survey were $53.33 \%$ male and $46.67 \%$ female. Majority $(66.67 \%)$ were aged between 18 and 25 years (Table 1). The participants were largely literate, $100 \%$ were tertiary level graduates.

\section{a hedonic scale}

In all the test methods, the nine-point Hedonic scale occupies a unique niche in terms of its general applicability to the measurement of product acceptance- preference. The hedonic 9-point scale showed in the Table 2 summarized the sensory evaluation test on the six cereals/soybean ogi.

\section{consumer acceptability}

FMZSB was the most preferred among the six cereals/soybean ogi and was the choice of $96.67 \%$ of 30 consumers surveyed. However, the mean acceptability score assigned was not significantly different $(\mathrm{P}<0.05)$ between the two other fermented samples, FMLSB and FSGSB (Table 2). This observation verifies the results of the sensory evaluation conducted prior to the consumer acceptability survey, which also had acceptability scores not being significantly different $(P<0.05)$.

\section{macro minerals composition of cereals/soybean ogi}

mineral elements are vital for the maintenance of our body health. Those that are required in our diet in large amounts $(>100 \mathrm{mg} /$ day $)$ are known as macro elements and those that are required in small amount $(<100 \mathrm{mg} /$ day $)$ are known as trace or micro-elements. Macro elements which include $\mathrm{Na}, \mathrm{K}, \mathrm{Ca}, \mathrm{Mg}$ and $\mathrm{P}$ have multiple roles within the body such as initiation of hormone production and speed up of the metabolic processes. Trace elements which include $\mathrm{Fe}, \mathrm{Cu}$, $\mathrm{Zn}, \mathrm{Cr}$ and $\mathrm{Mn}$ interact with vitamins and macro elements to enhance their effects on the body. However, the presence of these elements above permissible levels can cause various deficiency diseases. The levels of potassium, magnesium and calcium in cereals/soybean-ogi 
observed are summarized in Table 3. The average calcium content in cereals/soybean ogi were $3065.38 \mathrm{mg} / \mathrm{kg}$ for FSGSB, $2646.38 \mathrm{mg} / \mathrm{kg}$ for USGSB, $2533.74 \mathrm{mg} / \mathrm{kg}$ for UMZSB, $1741.15 \mathrm{mg} / \mathrm{kg}$ for FMZSB, $2394.78 \mathrm{mg} / \mathrm{kg}$ for UMLSB, and $1414.09 \mathrm{mg} / \mathrm{kg}$ for FMLSB (Table 3). These values vividly showed that all co-fermented samples had higher amount of calcium than their unfermented counterparts but this was not so in fermented sorghum/soybean. On the contrary, the fermented sorghum/soybean ogi (FSGSB) had the highest amount of calcium followed by its unfermented counterpart (USGSB). This result to a large extent, was not significantly different from the range of 1414$3136 \mathrm{ppm}$ for cereals/cowpea ogi reported by Oyarekua. ${ }^{1}$ This high value of calcium in cereals/soybean ogi compares well with the body requirements for the dietary calcium which is $2500 \mathrm{mg} /$ day. ${ }^{9}$ Calcium is an important mineral for bone and teeth formation as well as body structure and in blood clotting. Its deficiency can lead to rickets in infants and children and osteomalacia in adults.

Table 2 Sensory test on fermented and unfermented cereals/soybean ogi

\begin{tabular}{lllllll}
\hline Sensory Attribute & FMZSB & FMLSB & FSGSB & UMZSB & UMLSB & USGSB \\
\hline Likeness & $7^{\mathrm{a}}$ & $6^{\mathrm{b}}$ & $5^{\mathrm{c}}$ & $6^{\mathrm{b}}$ & $5^{\mathrm{c}}$ & $6^{\mathrm{b}}$ \\
Sweetness & $5^{\mathrm{a}}$ & $4^{\mathrm{b}}$ & $3^{\mathrm{c}}$ & $4^{\mathrm{b}}$ & $4^{\mathrm{b}}$ & $4^{\mathrm{b}}$ \\
Thickness & $5^{\mathrm{a}}$ & $4^{\mathrm{b}}$ & $4^{\mathrm{b}}$ & $4^{\mathrm{b}}$ & $4^{\mathrm{b}}$ & $4^{\mathrm{b}}$ \\
Aroma/Smell & $6^{\mathrm{a}}$ & $6 \mathrm{a}$ & $6^{\mathrm{a}}$ & $6^{\mathrm{a}}$ & $5^{\mathrm{b}}$ & $6^{\mathrm{a}}$ \\
Sour & $4^{\mathrm{a}}$ & $4^{\mathrm{a}}$ & $3^{\mathrm{b}}$ & $4^{\mathrm{a}}$ & $4^{\mathrm{a}}$ & $4^{\mathrm{a}}$ \\
Appearance & $6^{\mathrm{a}}$ & $6^{\mathrm{a}}$ & $5^{\mathrm{b}}$ & $6^{\mathrm{b}}$ & $5^{\mathrm{b}}$ & $6^{\mathrm{a}}$ \\
Saltiness & $4^{\mathrm{a}}$ & $4^{\mathrm{a}}$ & $3^{\mathrm{b}}$ & $4^{\mathrm{a}}$ & $4^{\mathrm{a}}$ & $4^{\mathrm{a}}$ \\
General acceptability & $4^{\mathrm{a}}$ & $3^{\mathrm{b}}$ & $3^{\mathrm{b}}$ & $3^{\mathrm{b}}$ & $3^{\mathrm{b}}$ & $3^{\mathrm{b}}$
\end{tabular}

Values are means of panelist's scores: 9, like extremely; 8, like very much, 7, like moderately; 6, like slightly; 5, Neither like nor dislike; 4, Dislike slightly; 3, Dislike moderately; 2, Dislike very much; I, Dislike extremely.

Means on the same column followed by the same letters are not significantly different according to least significant difference at $\mathrm{P} \leq 0.05$; FMZSB, Fermented maize/soybeans; FMLSB, Fermented millet/soybeans; FSGSB, Fermented sorghum/soybeans; UMZSB, Unfermented.

Table 3 Macro element composition $(\mathrm{mg} / \mathrm{kg})$ of cereals/soybean Ogi

\begin{tabular}{llll}
\hline Sample & $\mathbf{C a}$ & $\mathbf{M g}$ & $\mathbf{K}$ \\
\hline LSB & $2394.78^{\mathrm{d}}$ & $252.16^{\mathrm{d}}$ & $341.86^{\mathrm{b}}$ \\
UMZSB & $2533.74^{\mathrm{c}}$ & $281.92^{\mathrm{c}}$ & $339.4 \mathrm{I}^{\mathrm{c}}$ \\
USGSB & $2646.38^{\mathrm{b}}$ & $345.59^{\mathrm{a}}$ & $512.13^{\mathrm{a}}$ \\
FMLSB & $1414.09^{\mathrm{f}}$ & $184.98^{\mathrm{f}}$ & $290.02^{\mathrm{d}}$ \\
FMZSB & $1741.15^{\mathrm{e}}$ & $198.07^{\mathrm{e}}$ & $162.93^{\mathrm{f}}$ \\
FSGSB & $3065.38^{\mathrm{a}}$ & $316.4^{\mathrm{b}}$ & $278.49^{\mathrm{e}}$ \\
\hline
\end{tabular}

Means values with the same superscript in a column are not significantly different $(\mathrm{P}<0.05)$; UMLSB, represents unfermented Millet/Soybean; UMZSB, represents unfermented Maize/Soybean; USGSB, unfermented Sorghum/ Soybean; FMLSB, fermented Millet/Soybean; FMZSB, fermented Maize/Soybean; FSGSB, fermented sorghum/Soybean.

The amounts of potassium in all unfermented samples of cereals/ soybean ogi were significantly higher than their respective cofermented counterparts. This result indicated that fermentation led to a decrease in potassium contents of cereals/soybean ogi. This result strongly agrees with the data reported by Oyarekua, ${ }^{1}$ that co-fermented cereals/cowpea had lower potassium level than its unfermented counterparts. In this study, it can be inferred that all the samples except for FMZSB $(162.93 \mathrm{mg} / \mathrm{kg}$ ) had higher potassium level and as such they can contribute very much to the recommended daily allowance for potassium which is $2000 \mathrm{mg} /$ day for an adult. ${ }^{10}$ Although, fermentation appeared to have a decreasing effect on the potassium contents of all the co-fermented samples. Potassium is an extracellular cation bound to protein and sodium. It influences osmotic pressure and contributes to both homeostatic balance and normal $\mathrm{pH}$ equilibrium. Similarly, the magnesium content of all the samples followed the same trend. Co-fermented cereals/soybean ogi had significantly lower magnesium content compared with unfermented cereals/soybean ogi. This result suggested therefore that some macro elements leach out during the fermentation.

\section{micro mineral compositions of cereals/soybean ogi}

The results in Table 4 showed that fermented millet/soybean ogi (FMLSB) was the only sample with higher iron content than its unfermented counterpart while others had significant reduction in their iron compositions as a result of the fermentation processing. To some extent, this result partly disagrees with the reported data by Oyarekua, ${ }^{1}$ which stated that fermentation led to increase in iron content of cofermented cereals/cowpea samples. Iron is an important component of hemoglobin (oxygen-carrying pigment of red blood cell) and also iron acts as co-enzyme in the electron transfer. Infants, children and adults require iron to meet the need for red blood cells synthesis and growth since the red blood cell dies at 120 days . The amounts of iron required daily are $10000-15000 \mathrm{ppm}$ for children, whereas intakes of $50 \mathrm{mg}$ Fe per day or $25-75 \mathrm{mg}$ Fe by adults have cited as safe, but many individuals have taken iron medication at these or higher levels for extended periods without reported harm. ${ }^{11}$ Iron-deficiency anaemia affects young children it impairs physical and cognitive development and immune response to disease. Deficiency of iron can be mild when iron store is low in the body, can be severe when it is low in the blood level of haemoglobin. Symptoms of iron deficiency include fatigue, depressed growth and neuro-psychomotor development. ${ }^{1}$

The result in Table 4 also showed that all unfermented cereal/ soybean ogi recorded significantly higher copper content than their co-fermented counterparts. However, USGSB $(3.81 \mathrm{mg} / \mathrm{kg})$ had the highest amount of copper followed by UMLSB with $(2.8 \mathrm{mg} / \mathrm{kg})$ while FMZSB had the least $(1.97 \mathrm{mg} / \mathrm{kg})$. Copper helps in maintaining 
the integrity of myelin sheath surrounding the nerve fibers, bone and connective tissue formation, cardiovascular tissue and immune system of man. ${ }^{11}$

Table 4 Micro Element composition ( $\mathrm{mg} / \mathrm{kg}$ ) of cereals/soybean ogi

$\begin{array}{llll}\text { Sample } & \text { Fe } & \text { Cu } & \text { Zn } \\ \text { UMLSB } & 47.65^{\mathrm{e}} & 2.8^{\mathrm{c}} & 46.6^{\mathrm{c}} \\ \text { UMZSB } & 74.91^{\mathrm{c}} & 2.58^{\mathrm{b}} & 45.49^{\mathrm{d}} \\ \text { USGSB } & 100.2 \mathrm{I}^{\mathrm{a}} & 3.8 \mathrm{I}^{\mathrm{a}} & 46.97^{\mathrm{b}} \\ \text { FMLSB } & 97.91^{\mathrm{b}} & 2.1^{\mathrm{e}} & 28.39^{\mathrm{f}} \\ \text { FMZSB } & 41.93^{\mathrm{f}} & 1.97^{\mathrm{f}} & 31.59^{\mathrm{e}} \\ \text { FSGSB } & 72.3 \mathrm{I}^{\mathrm{d}} & 2.4 \mathrm{I}^{\mathrm{d}} & 49.3^{\mathrm{a}}\end{array}$

Means values with the same superscript in a column are significantly different $(\mathrm{P}<0.05)$; UMLSB, represents unfermented Millet/Soybean; UMZSB, represents unfermented Maize/Soybean; USGSB, unfermented Sorghum/Soybean; FMLSB, Fermented Millet/Soybean; FMZSB, fermented Maize/Soybean; FSGSB, fermented sorghum/Soybean.

The same sequence was recorded for unfermented maize and millet /soybean ogi had higher zinc content than its co-fermented counterparts unlike co-fermented sorghum/soybean (with $49.3 \mathrm{mg} / \mathrm{kg} \mathrm{Zn}$ ) which is higher than $46.97 \mathrm{mg} / \mathrm{kg} \mathrm{Zn}$ of USGSB. However, this result disagreed with the finding of Oyarekua ${ }^{1}$ which reported that co-fermented cereal/ cowpea had higher amount of zinc than its unfermented partners. Zinc plays an essential role in normal taste sensation, protein and nucleic acid synthesis, carbohydrate metabolism, successful pregnancy, delivery and normal development. ${ }^{11}$ Also, Rossaldo et al. ${ }^{12}$ reported that excess zinc may decrease the amount of high-density lipoprotein (HDL) circulating in the blood leading to risk of heart disease and this can affect the function of immune system. Zinc deficiency is prevalent in infants from developing countries because the diets are low in animal products and high in phytate. Diarrhoea is also an important cause of intestinal zinc loss. ${ }^{10}$ It can be deduced that the reduction in the mineral contents in all co-fermented cereals/soybean ogi may be due to leaching of the soluble inorganic salt during steeping, fermentation time (3-4days) and disposal of the steep water prior to milling. The losses may be attributed to loss during sieving and dewatering process.

The results in Table 5 summarized the proximate compositions of co-fermented and unfermented cereals/soybean ogi. It was observed that the crude protein in all the fermented cereals/soybean was significantly higher than unfermented samples. This pinpoints that fermentation improves the bioavailability of crude protein but this observation was in support of Uche et al., ${ }^{2}$ who reported that supplementation before fermentation (co-fermentation) improved crude protein, crude fat and ash but in total contrast to the finding of the publication by Oyarekua ${ }^{1}$. The result showed that FSGSB was ranked with the highest crude protein $(8.44 \%)$ followed by FMLSB $(6.64 \%)$ and least in UMZSB $(4.73 \%)$

Table 5 Proximate composition of cereals/soybean ogi

\begin{tabular}{|c|c|c|c|c|c|c|}
\hline Sample & \%C. Protein & \%C. fat & \%Ash & \%Moisture & \%C. fibre & $\% \mathrm{CHO}$ \\
\hline UMZSB & $4.73^{f}$ & $0.47^{f}$ & $2.7 \mathrm{I}^{\mathrm{f}}$ & $63.26^{\mathrm{e}}$ & $0.38^{\mathrm{b}}$ & $28.45^{\mathrm{a}}$ \\
\hline UMLSB & $5.38^{e}$ & $0.5^{\text {ed }}$ & $2.84^{\mathrm{ed}}$ & $63.76^{d}$ & $0.32^{\mathrm{ed}}$ & $27.2^{\mathrm{c}}$ \\
\hline USGSB & $6.33^{d}$ & $0.54^{\mathrm{ed}}$ & $2.8 I^{\text {ed }}$ & $61.55^{f}$ & $0.46^{\mathrm{a}}$ & $28.31^{b}$ \\
\hline FMZSB & $6.53^{c}$ & $0.6 \mathrm{I}^{\mathrm{c}}$ & $2.90^{c}$ & $67.35^{\mathrm{b}}$ & $0.30^{\mathrm{ed}}$ & $22.31^{\mathrm{e}}$ \\
\hline FMLSB & $6.64^{b}$ & $0.65^{b}$ & $2.97^{b}$ & $67.86^{\mathrm{a}}$ & $0.25^{f}$ & $21.63^{f}$ \\
\hline FSGSB & $8.44^{a}$ & $0.72^{\mathrm{a}}$ & $3.15^{\mathrm{a}}$ & $64.52^{c}$ & $0.34^{c}$ & $22.83^{d}$ \\
\hline
\end{tabular}

Means with the same superscript in a column are not significantly different $\mathrm{P}<0.05$.

Similar trend of values was recorded for crude fat, all the co-fermented the bioavailability of divalent cations by the formation of insoluble cereals/soybean ogi had higher crude fat content than its unfermented complexes. This observation was in consonance with Oyarekua ${ }^{1}$ and counterparts unlike Oyarekua ${ }^{1}$ that reported higher lipid content in Muahamad et al. ${ }^{14}$ which stated that fermentation led to significant unfermented cereals/cowpea than its co-fermented analogues This reduction of phytate, proanthocyanidin content in cereals and sequence of values was also observed in ash and moisture content, vegetables.

whereby all co-fermented cereals/soybean ogi had higher moisture and ash content than their respective unfermented counterparts. ${ }^{12}$ Conversely, fermentation had depreciative effect on the crude fibre contents of cereals/ soybean ogi. All unfermented cereals/soybean ogi contained slightly higher crude fibre than co fermented cereals/soybean ogi. Although, this result was at par with Oyarekua ${ }^{1}$ but the range of values for crude fibre $(0.25-0.46 \%)$ in cereals/soybean ogi was significantly lower than that of cereals/cowpea ogi $(3.0-4.9 \%)$.

Table 6 showed the summary of anti-nutrient content of cereals/ soybean ogi. From the result, all the co-fermented cereals/soybean ogi experienced drastic reduction in both phytate and tannin content when compared to its unfermented counterparts. The low level of phytate appeared to have positive correlation with the bioavailability of zinc in cereals/soybean ogi. This result supported the assertion by Weaver $\&$ Kanna $^{13}$ that phytic acid as a powerful chelating agent reduces

Table 6 Anti-nutrient content of cereals/soybean pap

\begin{tabular}{lll}
\hline Sample & \% phytate & $\%$ Tannin \\
\hline UMZSB & $0.34^{\mathrm{b}}$ & $0.18^{\mathrm{b}}$ \\
UMLSB & $0.19^{\mathrm{d}}$ & $0.18^{\mathrm{b}}$ \\
USGSB & $0.42^{\mathrm{a}}$ & $0.22^{\mathrm{a}}$ \\
FMZSB & $0.16^{\mathrm{f}}$ & $0.12^{\mathrm{d}}$ \\
FMLSB & $0.18^{\mathrm{e}}$ & $0.13^{\mathrm{c}}$ \\
FSGSB & $0.26^{\mathrm{c}}$ & $0.13^{\mathrm{c}}$
\end{tabular}

Means values with the superscript in a column are significantly different $(P<0.05)$.UMLSB, Unfermented millet/soybean; UMZSB, Unfermented maize/ soybean; USGSB, Unfermented sorghum/soybean; FMLSB, fermented millet/ soybean; FMZSB, fermented maize/soybean; FSGSB, Fermented sorghum/ soybean. 


\section{Conclusion}

The results of this study demonstrated that joint fermentation of cereals and soybean improved its crude protein, crude fat, and ash and moisture composition. The macro minerals $(\mathrm{Ca}, \mathrm{K}$ and $\mathrm{Mg}$ ) and micro elements $(\mathrm{Fe}, \mathrm{Cu}$, and $\mathrm{Zn}$ ) were degraded by the fermentation except for FMLSB which had higher iron content compared with unfermented counterparts. Fermented maize /soybean ogi was the most preferred sample. Fermentation had improved the organoleptic properties of cereals/soybean ogi. Phytate and tannin anti-nutrient factors were drastically reduced by the co-fermentation of cereals/ soybean. Sorghum/soybean and its fermented counterpart were relatively higher in mineral elements. Right choice of the cereals/ soybean combination will be the best complementary food for infants.

\section{Acknowledgements}

The authors were grateful to the staff of SMO laboratories for thoroughly carrying out the bench work.

\section{Conflict of interest}

The authors declared that no conflict of interest exists.

\section{References}

1. Oyarekua MA. Sensory evaluation, nutritional quality and anti-nutritional factors of traditionally co-fermented cereals/cowpea mixtures as infant complementary food. Agriculture and Biology Journal of North America. 2010;1(5):950-956.

2. Uche BJ, Gibson RS, Perlas L, et al. Improving the bioavailability of nutrients in plant food at the house level. Proc of Not Society. 2008;(65):160-168.

3. Wang N, Lewis MJ, Breman JG, et al. Effect of processing method nutrients and anti-nutritional factors in soybean. Food Chemistry. 1997;58(1-2):59-68.
4. Stone H, Sidel JL. Sensory Evaluation Practices. 3rd ed. Elsevier Academic Press, San Diego, California; 2004: p. 408.

5. Lawless HT, Heymann H. Sensory evaluation of food principles and practices. 2nd edn. Springer Science and Business Media, LLC, New York; 2010.

6. AOAC. Official Methods of Analysis of the Association of Analytical Chemists International. 18th edn. Gathersburg, USA; 2005. p. 2308.

7. Ranganna S. Manual of analysis of fruit and vegetable products. Tata Mac Graw Hill Company Ltd, New Delhi; 1977:21-60.

8. Maga JA. Phytate: Its chemistry: Occurrence, food interactions, nutritional significance and method of analysis. Food chemistry. 2018;30(1):1-9.

9. NRC (National Research Council). Recommended Dietary Allowances. 10th edn. Washngton, DC, National Academy press; 1989. p. 42.

10. WHO/NUT. Complimentary Feeding of Infants and Young Children. Report of A Technical Consultation Supported by WHO/UNICEF, University of California/Davies abd ORSTOM; 1998.

11. Onigbinde AO. Food and Human Nutrition: Biochemical integration. Revised Edn. Alva Corporate Organisation, Benin City. Nigeria. 2005;326-333.

12. Rosaldo JLP, Lopez HM, Allen LH. Zinc supplementation reduced morbditybut neither zinc nor iron supplementation affected growth or body composition of Mexican pre-schoolers. Am J Clin Nutr. 1997;65(1):13-19.

13. Weaver CM, Kanna S. Phytate and mineral bioavailability. In: Reddy NR, Sathe SK, editors. Food Phytate. CRC Press Boca Raton; 2002:211-224.

14. Muahamad N, Faqir MA, Rai MA, et al. An overview of anti-nutritional factors in cereal grains with special reference to wheat-A review. Pak J Food sci. 2010;20(1-4):54-61. 